\title{
Survey To See The Impact Of 5s Implementation Among Staff Of Kpj Seremban Specialist Hospital,Malaysia
}

\author{
${ }^{1}$ AR.Abdul Aziz,${ }^{2}$ MB. Nishazini, ${ }^{3}$ Fareza,${ }^{4}$ N.A.Azizan \\ ${ }^{1,2,3}$ kpj Seremban Specialist Hospital, ${ }^{4}$ University Malaysia Pahang
}

\begin{abstract}
A survey was conducted in KPJ Seremban Specialist Hospital, Malaysia in July 2013. The survey forms were distributed to 330 staff consisting of questionaires which is divided into two sections. The first section was related to productivity, quality of work's place and proses in carrying out those works, quality of staff and morale of workers and safety of work's place. The second section was related to knowledge and understanding among staff. 234 (70.9\%) respondent had returned the survey form. It was found that before the implementation of 5S, the scores varies from poor to good( scoring from 1-3) related to the impact on productivity for quality of working place, quality and moral of staff and safety of work place but after the implementation of $5 S$ the scores had changed from good to excellent(scoring from 3-5). For the second section ,the staff had given 100\% scoring for the commitment towards clean, safe and condusive working place, $64 \%$ scoring on the necessity to immediately disposed items that had been segregated, 99\% scoring for the important of arrangement for easy searching /putting back the items, 99\% scoring for the important of schedule for cleaning of work place to ensure it is free from dust and 99\% scoring on the important of 5S as a good management system.
\end{abstract}

Keywords :survey, productivity, quality and safety, knowledge and understanding, 5S

\section{Introduction}

5S uses a list of five Japanese words: seiri,seiton,seiso,seiketsu, and shitsuke .It isa workplace organization method to organize a work space for efficiency and effectiveness by identifying and storing the items used, maintaining the area and items, and sustaining the new order. Understanding among employees of how they should do the work was done through dialogue before the decision-making process.(

Significant effects on the sequence of activities is directly influence by the implementation of $5 \mathrm{~S}$ which will directly influencing the performance of processes in the company (Dulhai 2008). 5S is a sequence of activities that is an effective tool for housekeeping or organization of supplies in healthcare. Sun and Yanagawa (2006) conducted a project by implementing 5S and one-piece flow to improve the services of the college union in an institute. Studies show that emphasis was given to monetary gains rather than arriving at a self sustained approach which will be able to identify root causes and provide solutions to excess inventory issues although traditionally $5 \mathrm{~S}$ has been an effective tool in organizing and maintaining a suitable work environment. $5 \mathrm{~S}$ is a systematic Lean tool and the simplest to implement for organizing and standardizing the workplace (Kilpatrick, 2003). Ho (1999) described 5S practice as a technique to establish and maintain a quality environment in an organization.Traditional $5 \mathrm{~S}$ has showed the importance of incorporating $5 \mathrm{~S}$ in day-to-day activities that ensure an error-free process.

Most Japanese $5 \mathrm{~S}$ professionals consider the $5 \mathrm{~S}$ as a tool to improves the physical environment and the thinking processes (Ho, 1999). From Japan, its benefits spread across the western 15 countries and translated in English. Ho (1999) provided English translation for the 5S such as structurize, systematize, sanitize, standardize, and self-discipline. 5S implementation has seen in diverse fields due to its simple and immediate results. As described by Kilpatrick (2003), 5S provides immediate returns on investment and is applicable to a diverse function of organizations and in the past, several organizations have successfully implemented 5S. Researchers have shared their experience during the implementation of $5 \mathrm{~S}$ and its impact after the event.According to Zidel (2006), 5S creates a solid foundation for future Lean initiative and can be implemented by any organization. Esain et al. (2008) identified 5S as a structural method to speed up operational change and focused on overseeing workplace discipline and control. Similarly, the study conducted by Khamis et. al (2009) also focused on a structural method to transform the $5 \mathrm{~S}$ process by providing adequate training to the employees starting with input for $5 \mathrm{~S}$ to the result. Past studies have paved way for an effective way in conducting a $5 \mathrm{~S}$ event and the necessary goals to be achieved. However, a major weakness is that most of the papers emphasized more on sharing ideas and ways to beautify a workplace, rather than achieving quality

To identify whether the implementation has been undertaken correctly and enables to detect issues that can be immediately dealt with by providing suitable solutions, an audit tool is essential which are available in the literature that provides a quick check on the $5 \mathrm{~S}$ implementation process.Khamis et. al (2009) focused on developing a $5 \mathrm{~S}$ practice checklist for the manufacturing industry by conducting surveys with two companies by 
considering housekeeping, environmental performance, health and safety, and analyzing the checklist record. They used two ranking systems for analyzing the condition of the companies in this study that are Likert scale and percentage value. The Likert Scale used in their study was to determine the level of implementation of the $5 \mathrm{~S}$ practice for each aspect in a developed checklist with 5 being the highest and 1 the lowest (Khamis et. al, 2009). Ho (1999) developed the idea of introducing a $5 \mathrm{~S}$ audit tool that effectively deals with identifying the non-conformance in an organization which was designed to suit any organization, by means of 50 questions for the five stages of 5S, which are Sort, Set-to-order, Shine, Standardize and Sustain. The scoring technique developed by Ho (1999) in his audit tool considers an evaluation of a total number of non-conformance activities for a total score of 50. The ratings obtained from these questions indicate the success of a $5 \mathrm{~S}$ event.

KPJ Seremban Specialist Hospital is working towards $5 \mathrm{~S}$ certification which will be conducted by the Malaysian Productivity Council.The implementation of 5S practices started early 2013 with many sessions of training of the stearing committee members followed by training of all staff.Many activities had been carried out to educate staff with knowledge and experiences. All activities had been carried out successfully because of full commitment among staff and management.Sixth months after the implementation of $5 \mathrm{~S}$, a survey was conducted to see the impact of 5S implementation among staff of KPJ Seremban Specialist Hospital.

\section{Objectives}

I.To Find Out The Level Of Understanding Among Staff On The Effectiveness Of 5S Before And After The Implementation. The Impact Will Be Focused On Productivity, Quality Of Work's Place And The Process Of Works, Quality Of Output And The Morale Of Staff.

Ii.To Find Out The Immediate Impact And Changes After The Implementation Of 5S

Iii. To Find Out The Level Of Knowledge Among Staff And Their Understanding On 5S

\section{Methodology}

Survey forms were distributed to three hundred and thirty staff (330) working in KPJ Seremban Specialist Hospital in the month of July 2013. The survey form was divided into two sections. The first section consist of four subsections(impact) related to productivity, quality of work's place and proses in carrying out those works, quality of staff and morale of workers and safety of work's place. Under the productivity the questions are related to arrangement of goods, files,working space,equipment, time to trace files, stock control,efficiency of space and cost.For quality of work's place and process in carrying out those works ,questions are related to efficiency of work process,achievement of objectives,cleanliness, comfortability of rooms for general use and implementation of $3 \mathrm{~S}$ (recycle, reuse and renew) program.Under quality of staff and moral of workers, questions are related toawareness on 5S, team work, creativity and innovation,working culture, self discipline, communication and health status of staff.For safety of work's place, questions are related to usage of equipment, the risk and comfort of working area.Rating of all questions are done based on the scale from 1 to 5 where 1 represent poor, 2 for fair, 3 for good, 4 for very good and 5 for excellent.In the second section, respondents are required to give the answer as YES or No for questions listed in the survey form which were related to knowledge and understanding among staff.

\section{Results}

$234(70.9 \%)$ respondent had returned the survey form .

Data of statistic based on demography of respondent.

\section{i. $\%$ based on category of services}

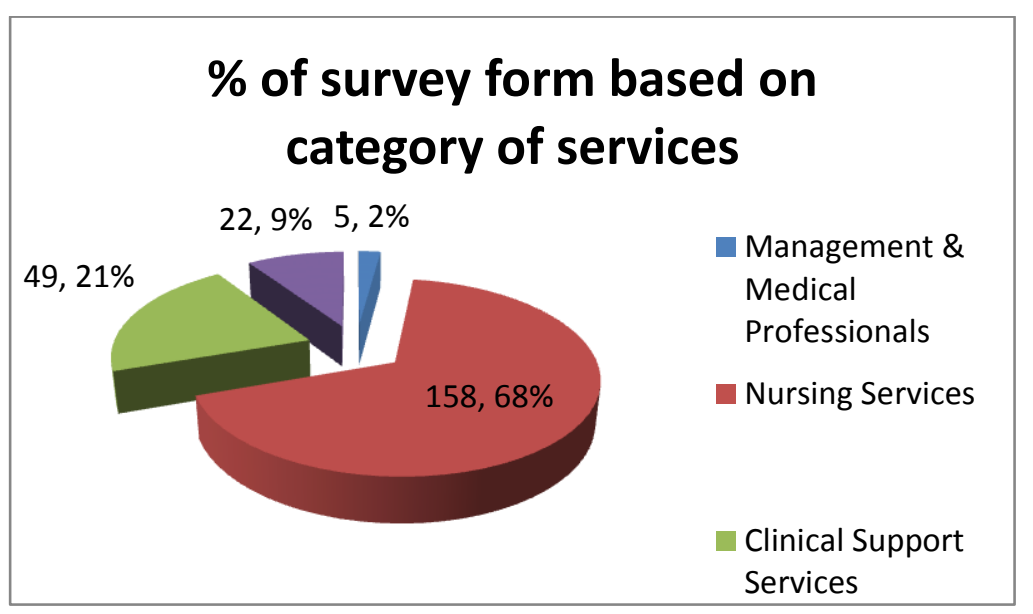


ii. Based on sex

\section{$\%$ based on sex}

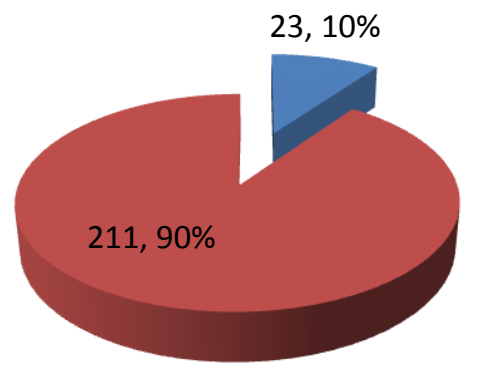

iii. Based on years of service

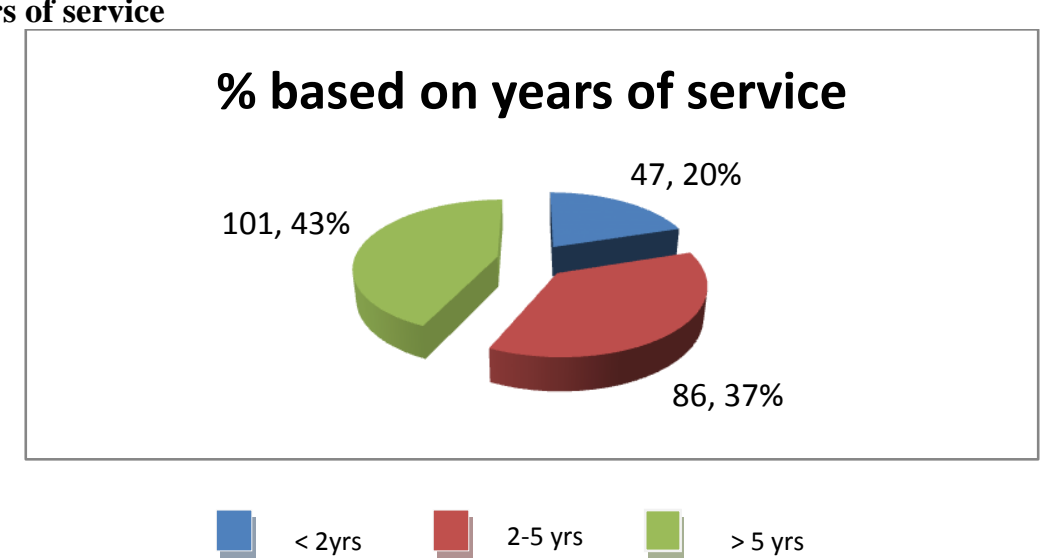

1. Data of survey for the first section(impact)

a.Impact 1 : Productivity

i. Arrangement of equipment/items in stor

\section{arrangement of equipment/items in stor}

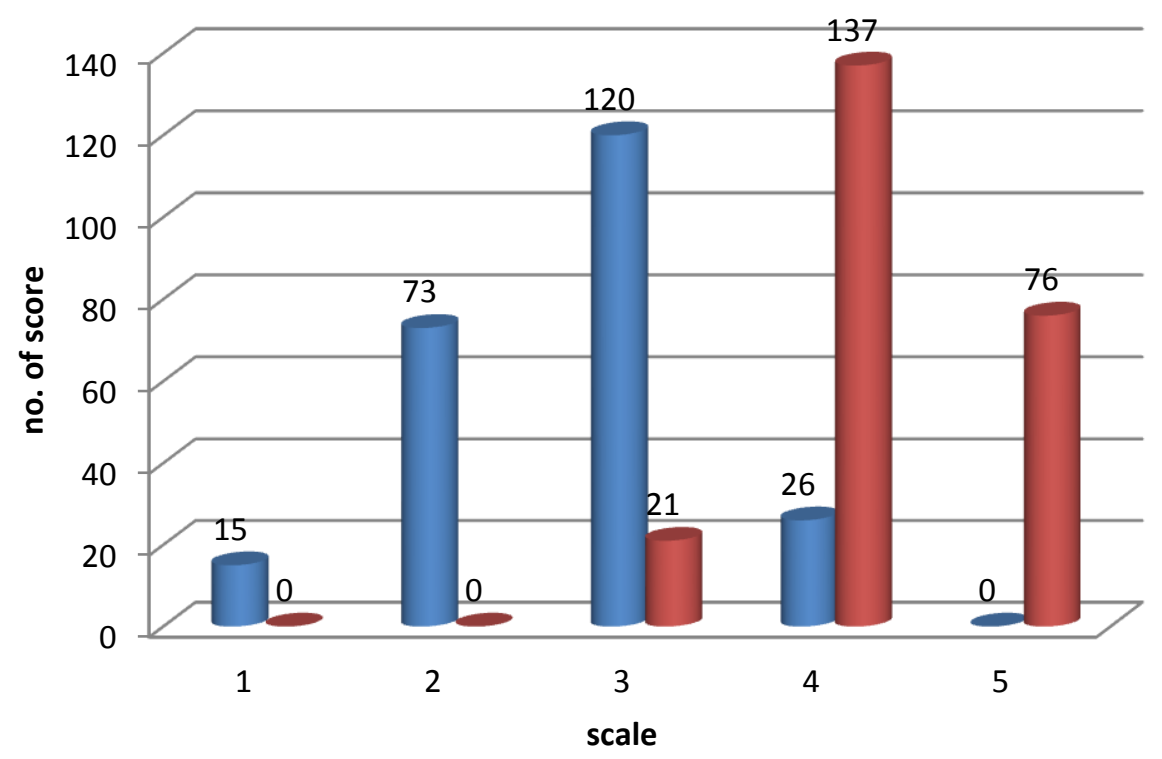


ii. file arrangement

\section{file arrangement}

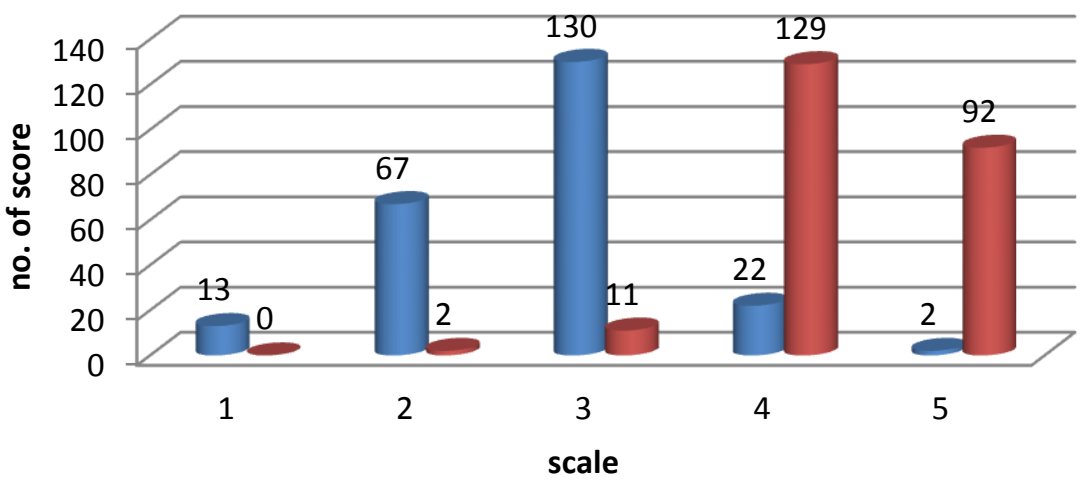

BEFORE $5 S$

AFTER5S

iii. arrangement of work place

\section{arrangement of work place}

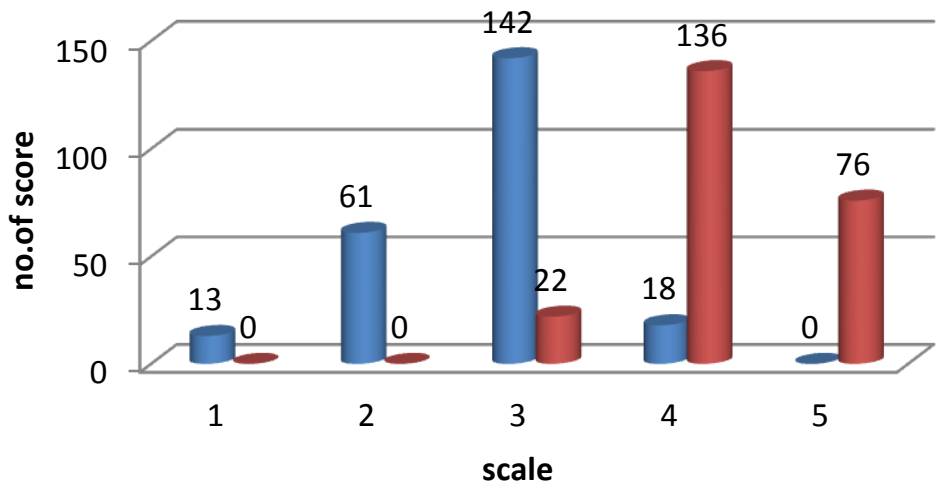

iv. usage of equipment

BEFORE $5 \mathrm{~S}$

AFTER5S

usage of equipment

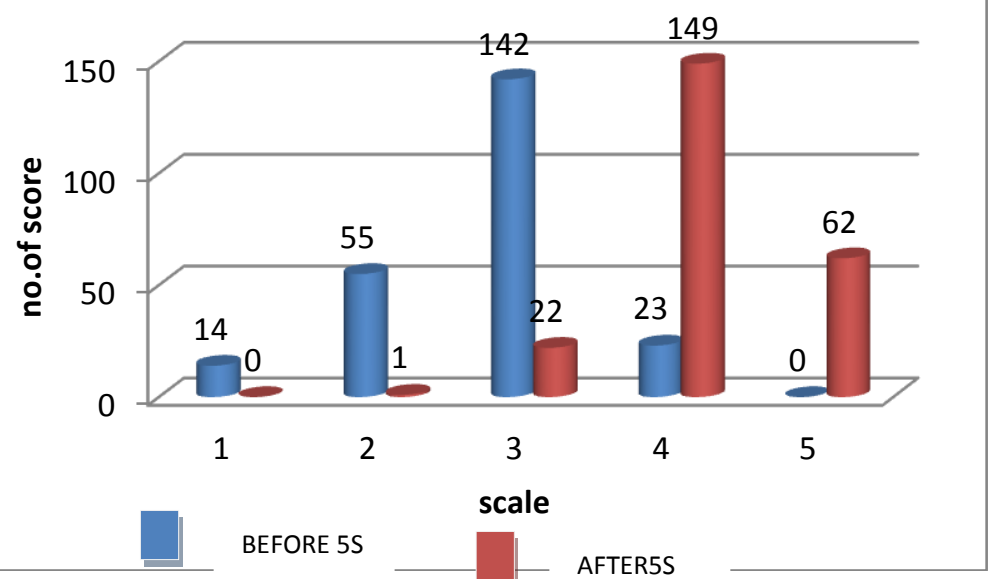


v. time taken for searching

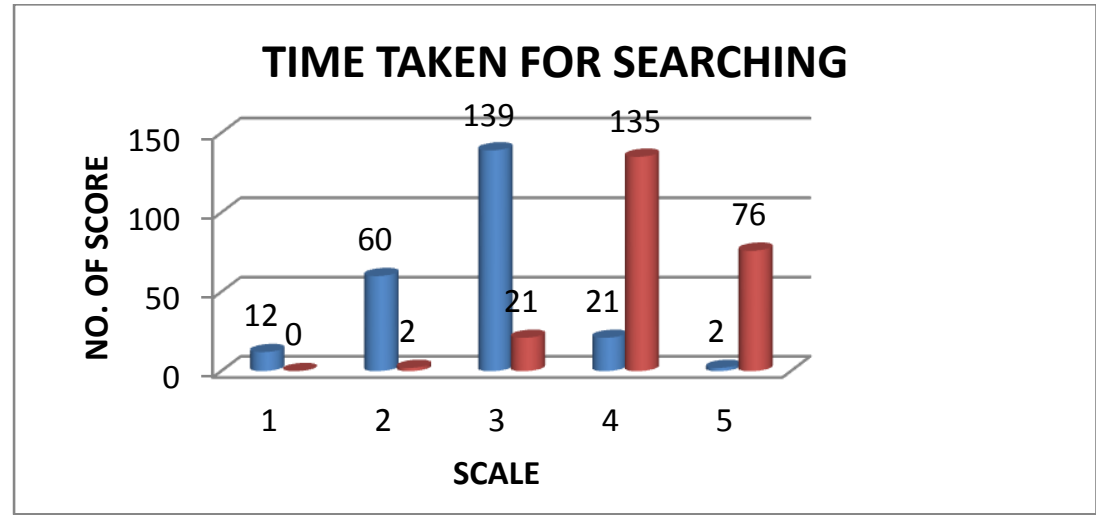

BEFORE 5S

AFTER5S

vi.stock control

\section{stock control}

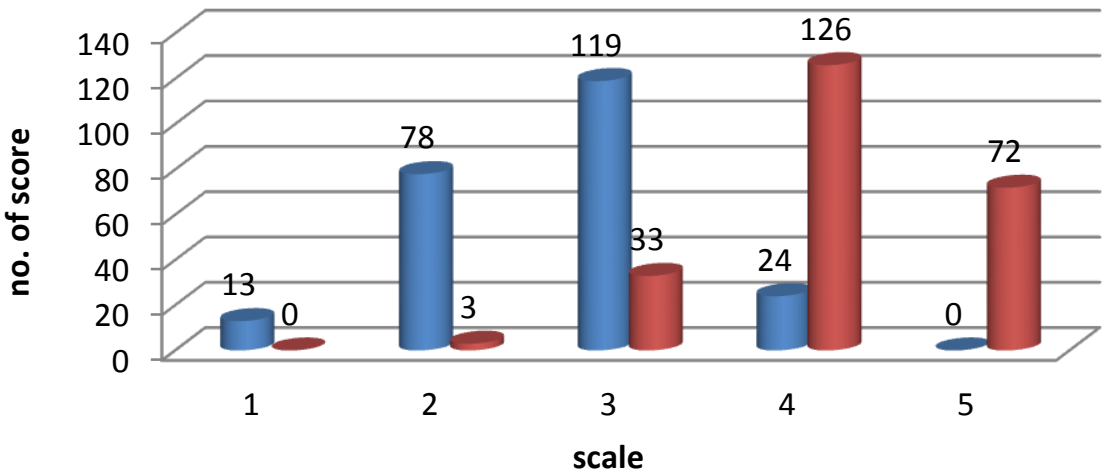

BEFORE 5S

vii. efficiency of space

efficiency of space

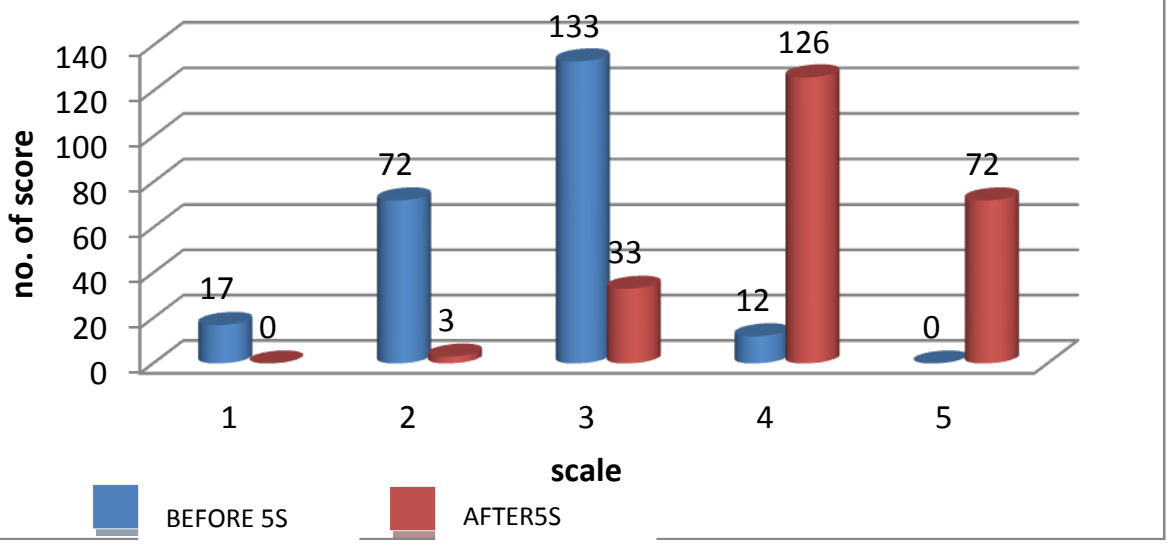


viii.cost saving

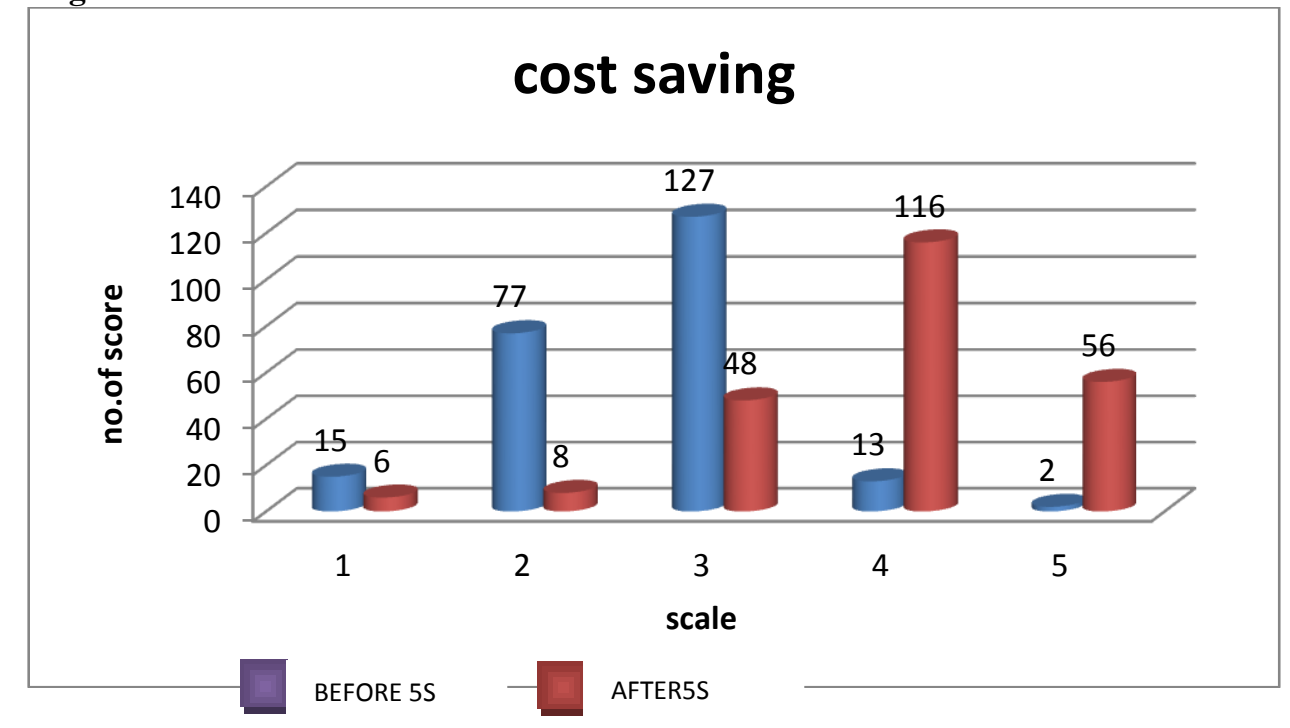

b.Impact 2: quality of work's place and proses in carrying out those works

i. efficiency of work process

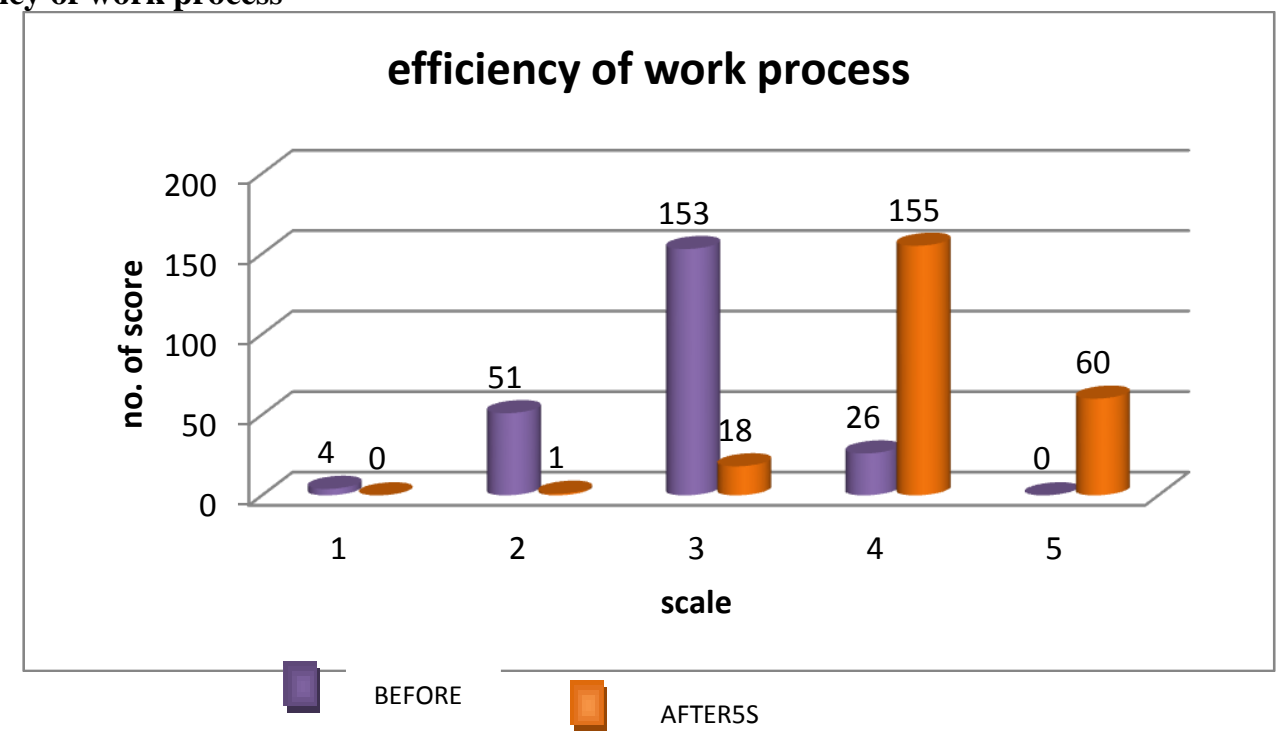

ii. achievement of objectives

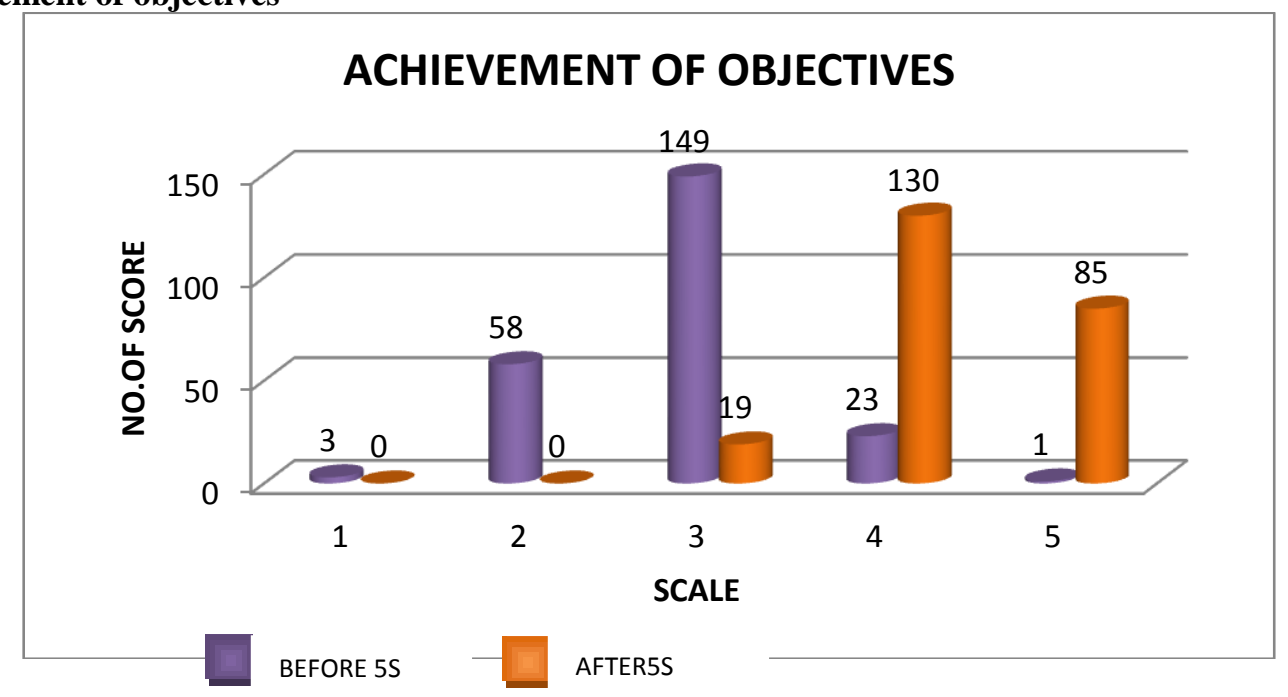


iii.cleanliness

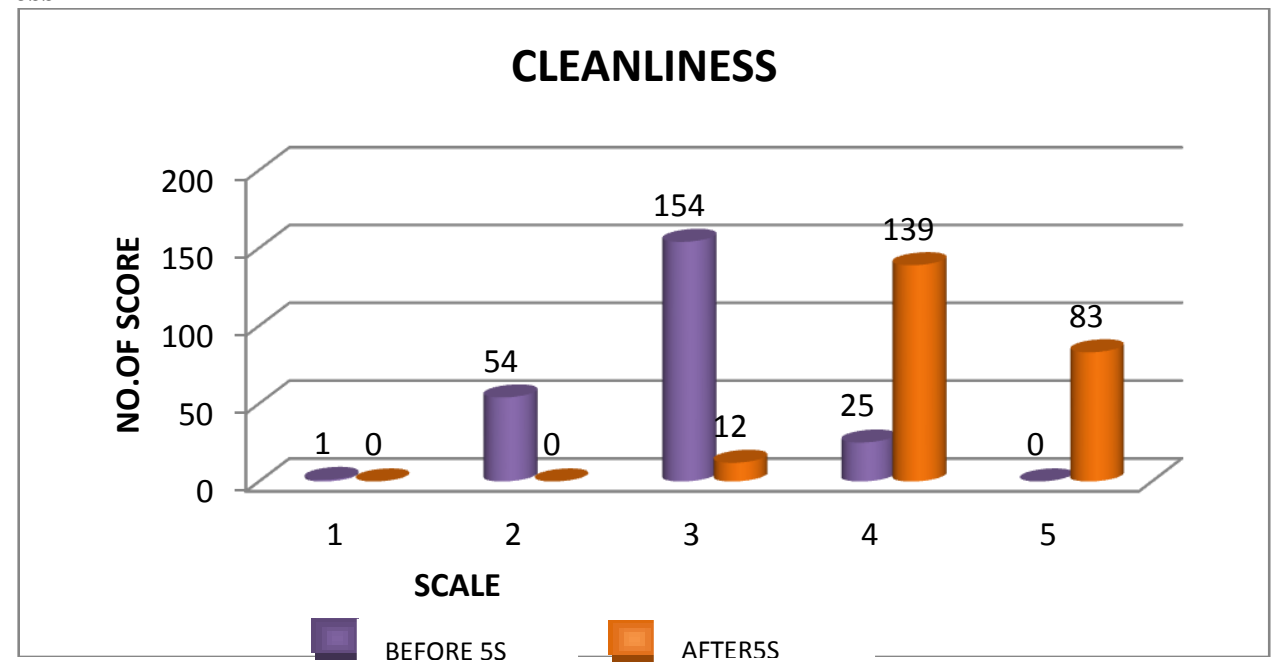

iv. comfortability of rooms for general use

\section{COMFORTABILITY OF ROOMS FOR GENERAL USE (pantry/toilet /prayer room)}

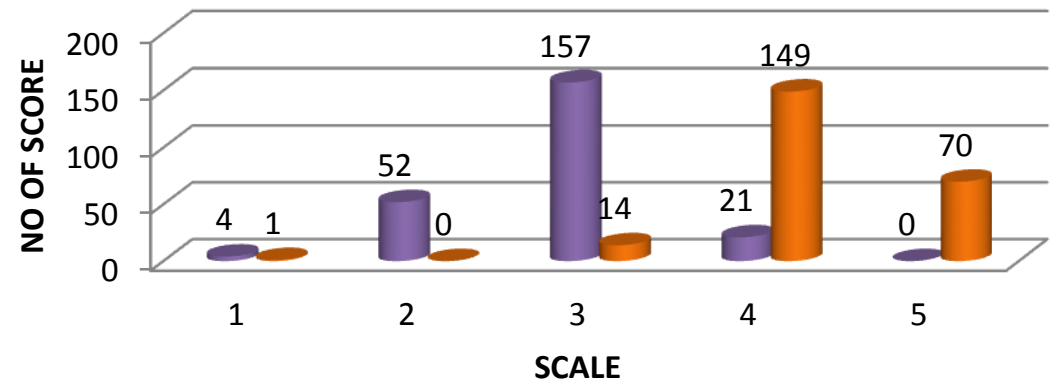

BEFORE $5 S$

AFTER5S

v.implementation of $3 R$ program

IMPLEMENTATION OF 3R PROGRAM

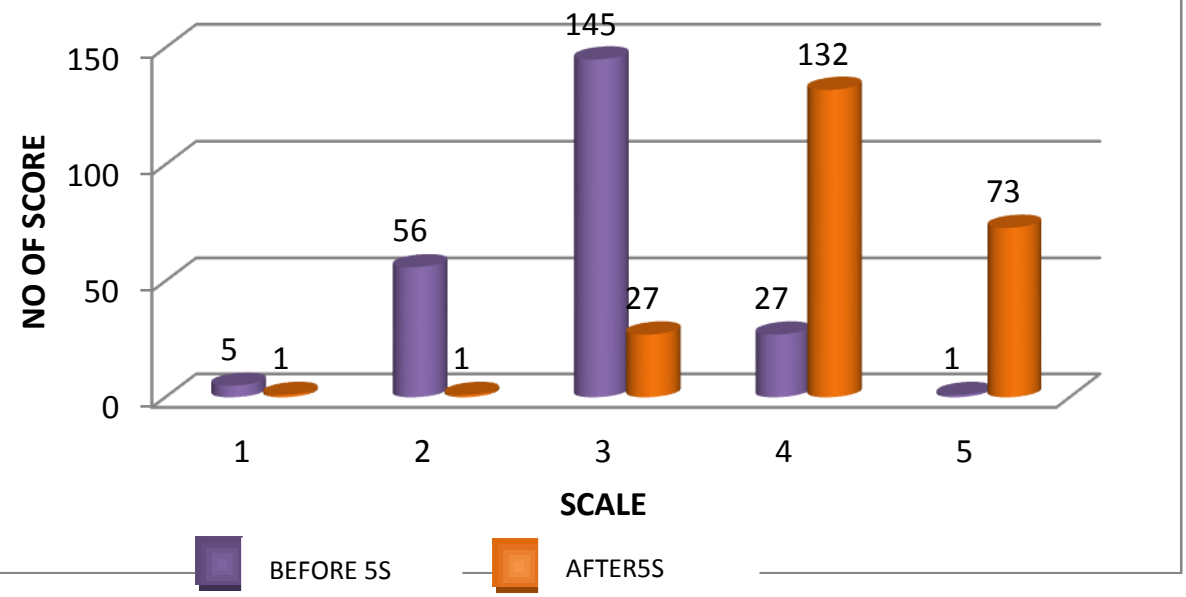


c.Impact 3. quality of staff and moral of workers i. awareness on $5 \mathrm{~S}$

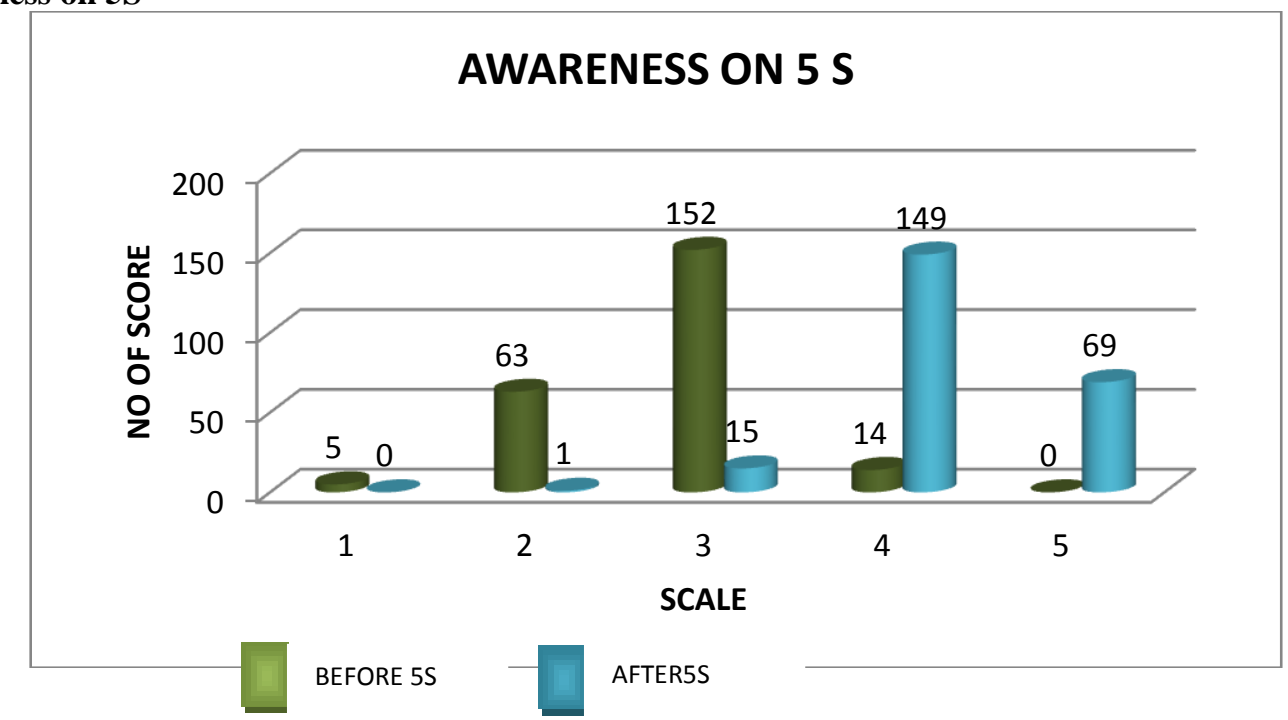

ii. team work

\section{TEAM WORK}

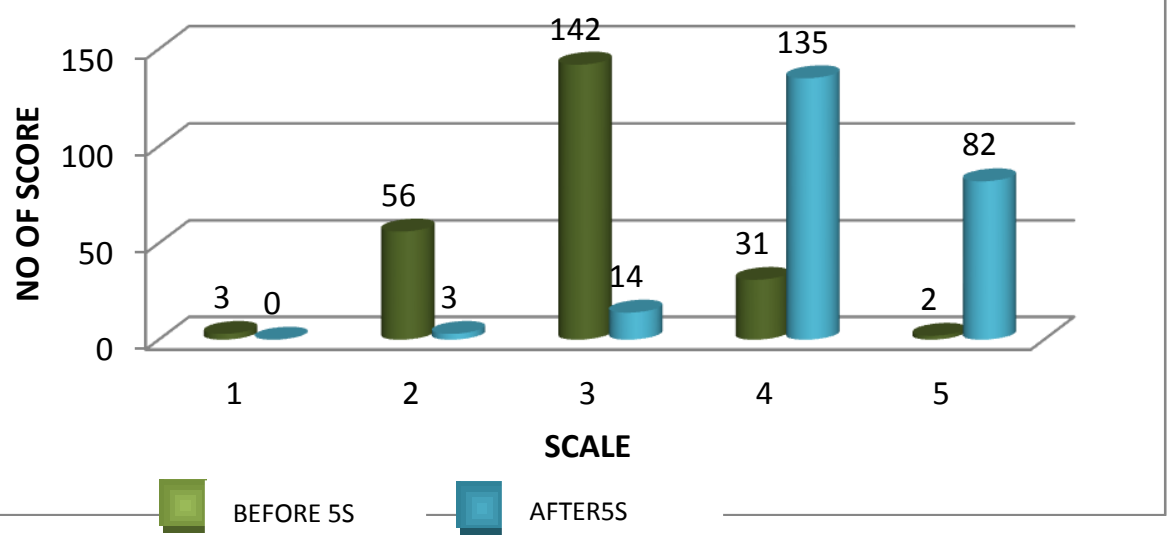

iii. creativity and innovation

\section{CREATIVITY AND INNOVATION}

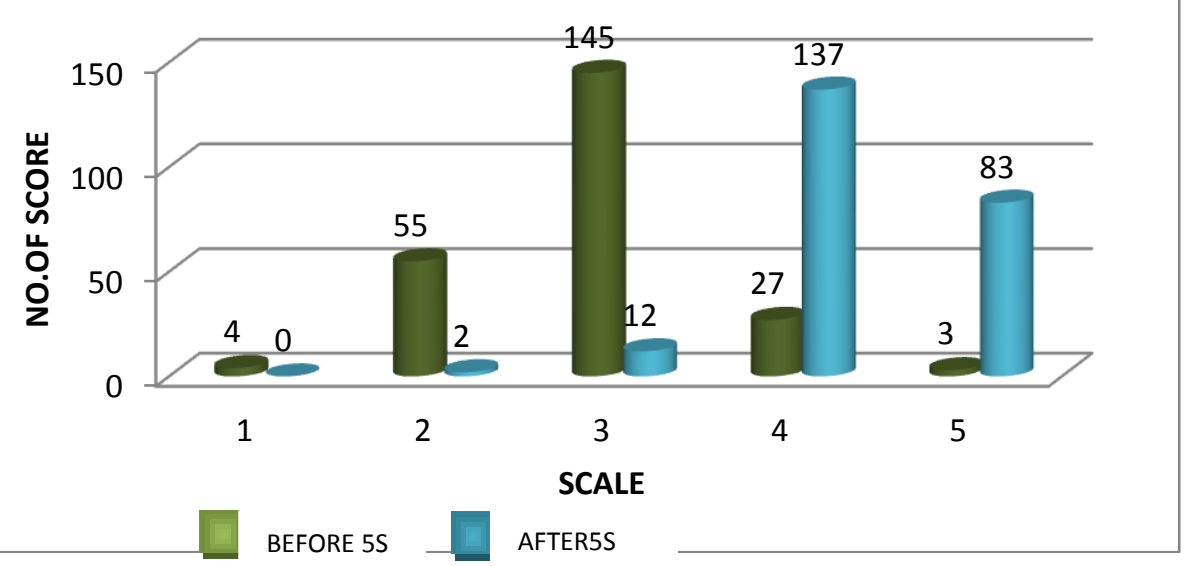


iv. working culture

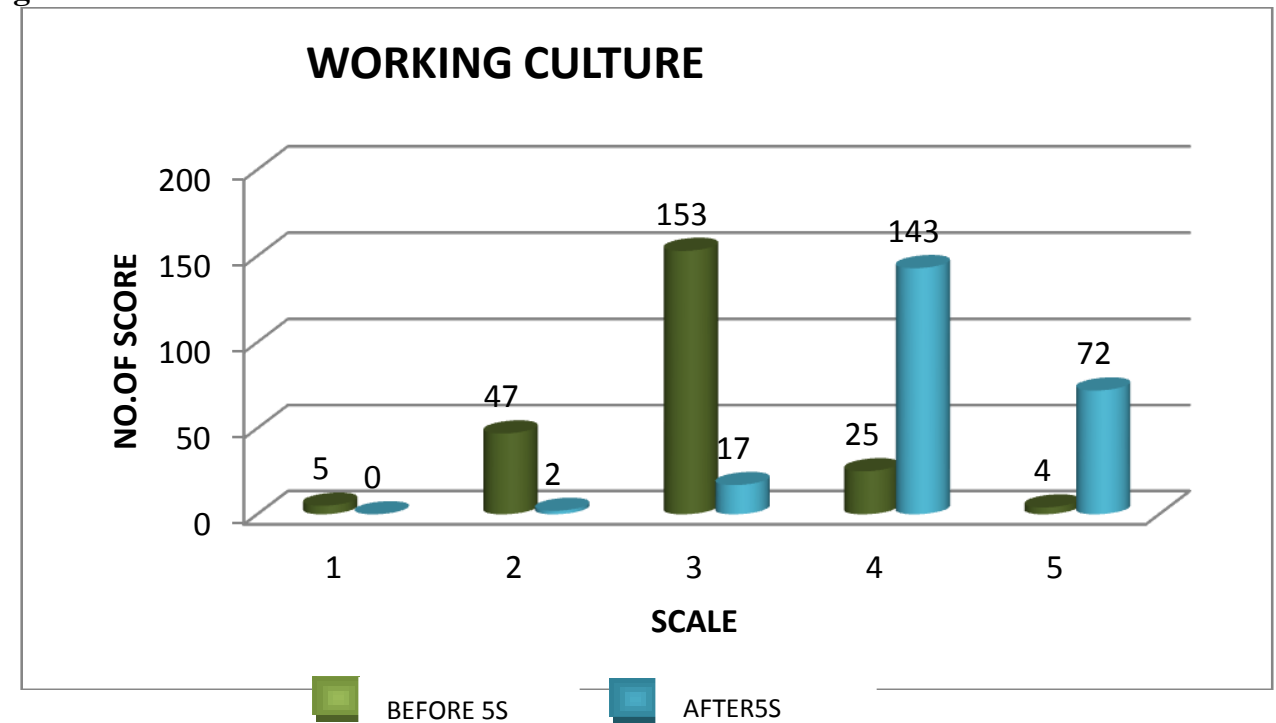

v. self discipline

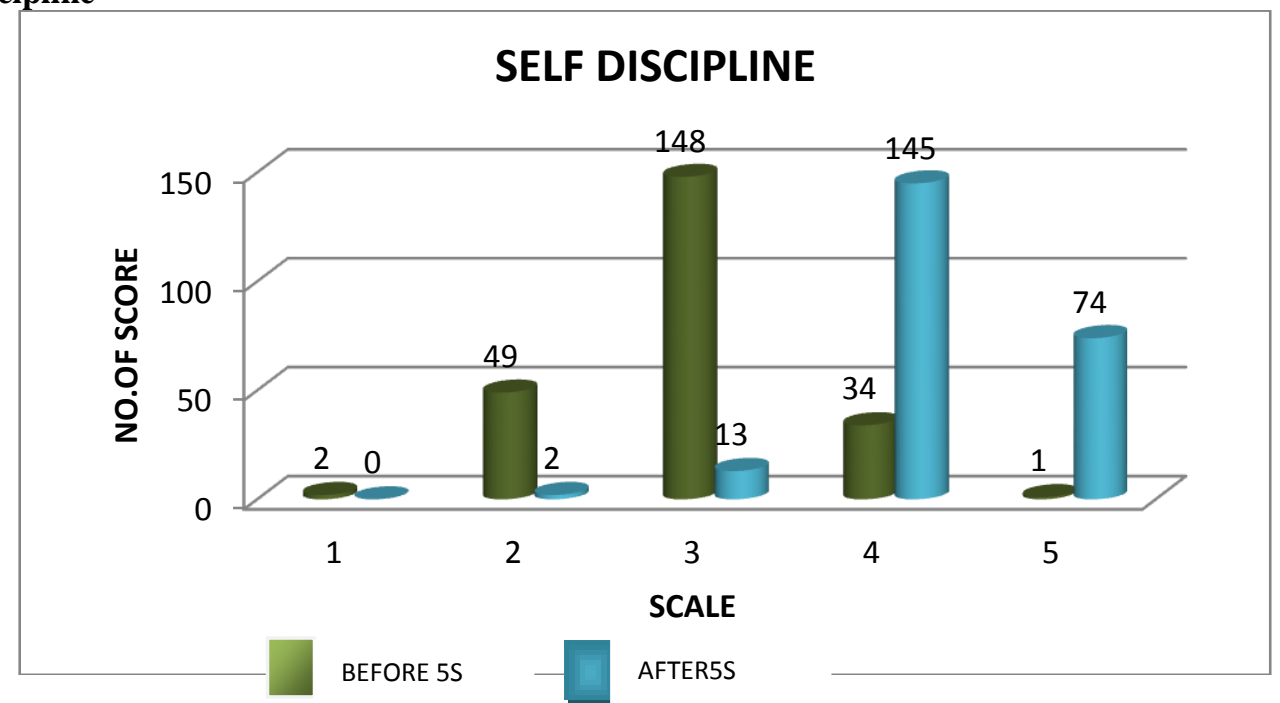

vi. communication

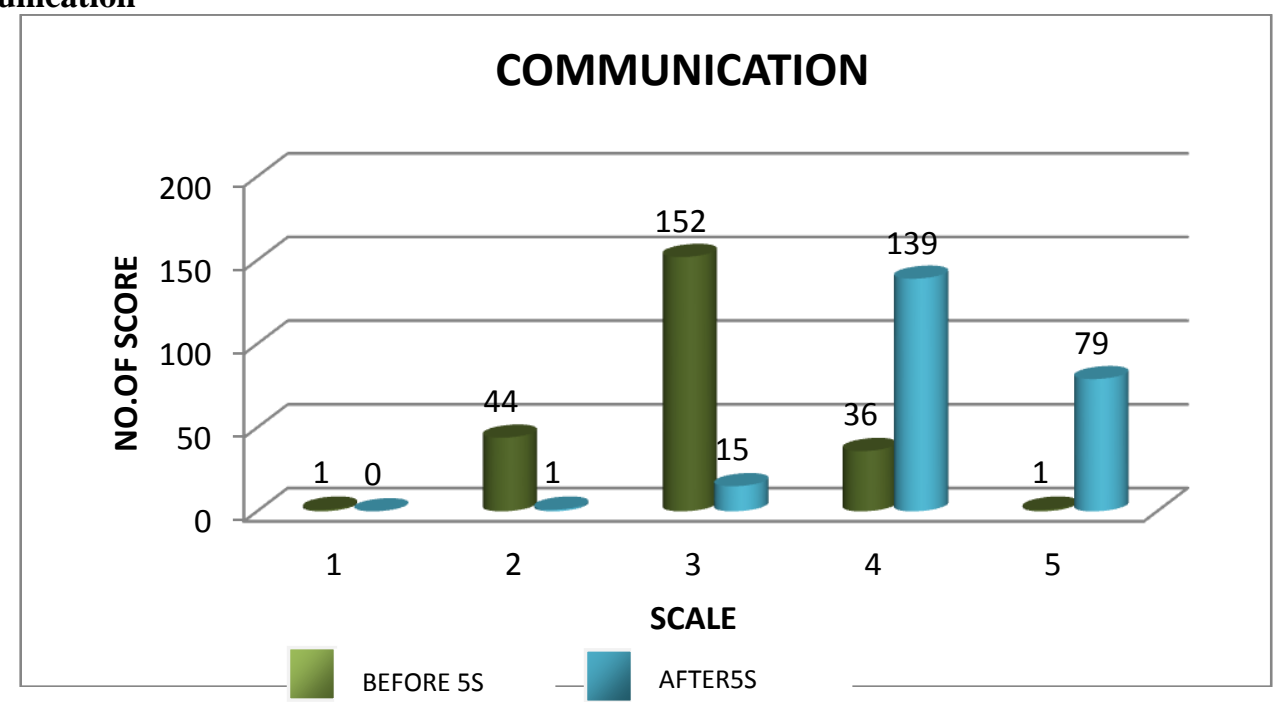


vii. health status of staff

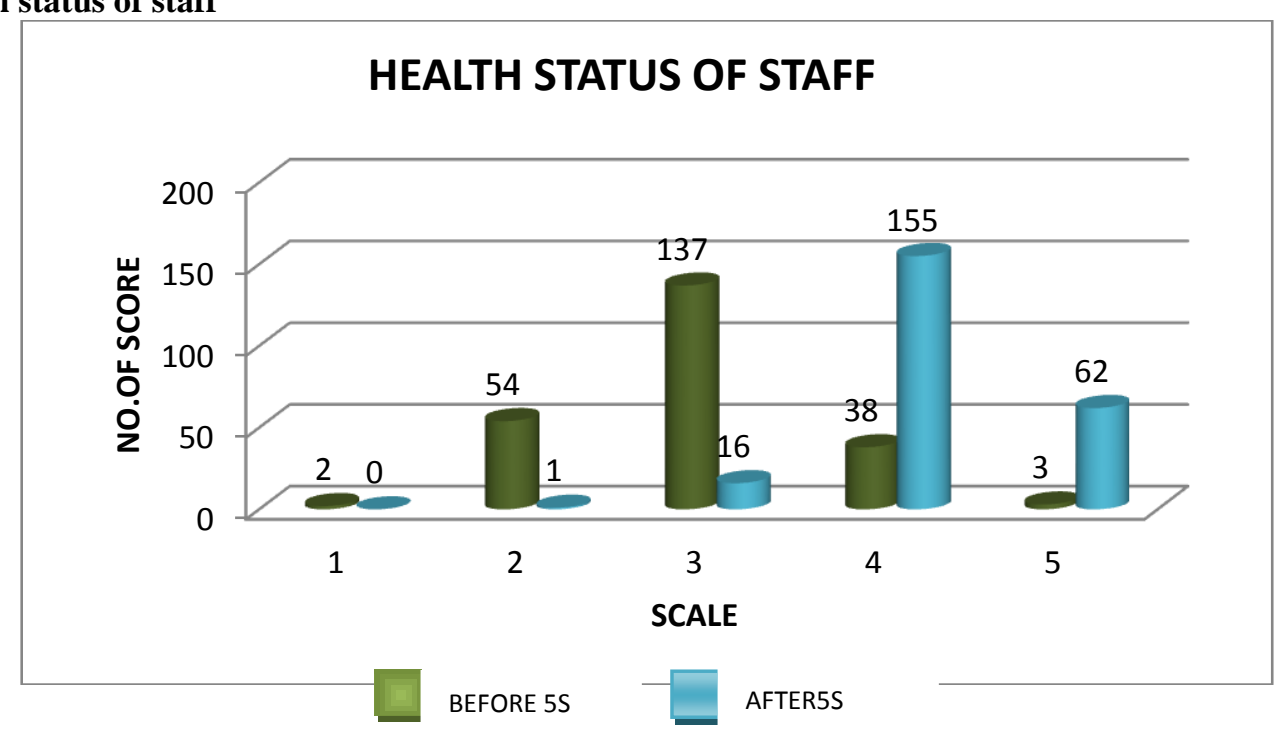

d. Impact 4 : safety of work's place

i. usage of equipment

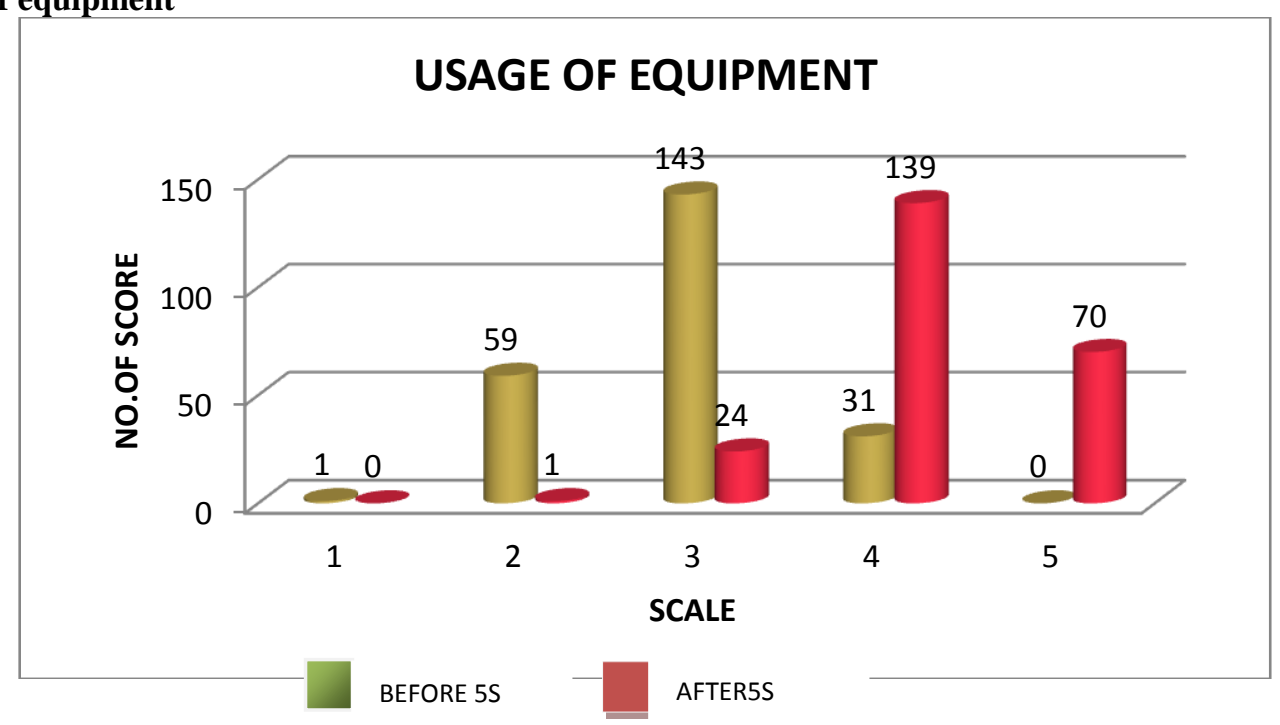

ii. Risk of accident

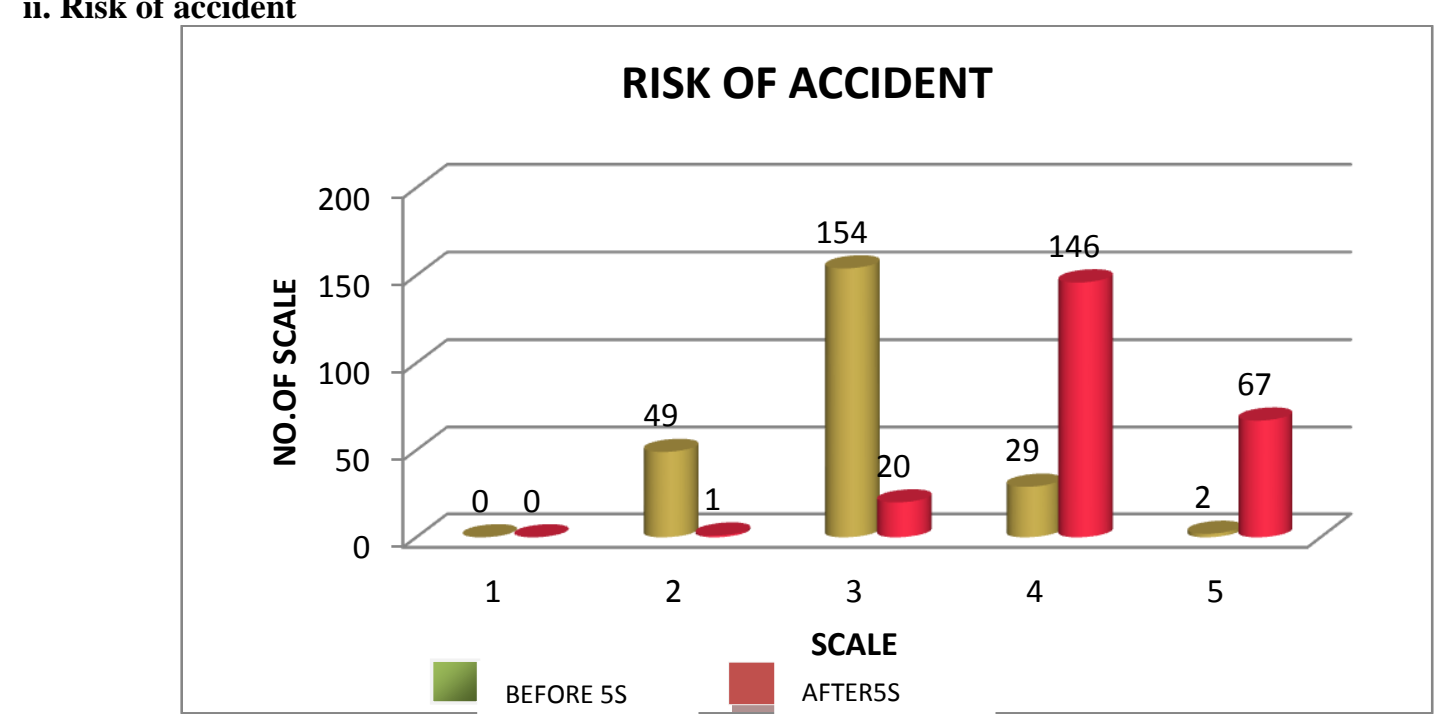


iii. comfort of working area

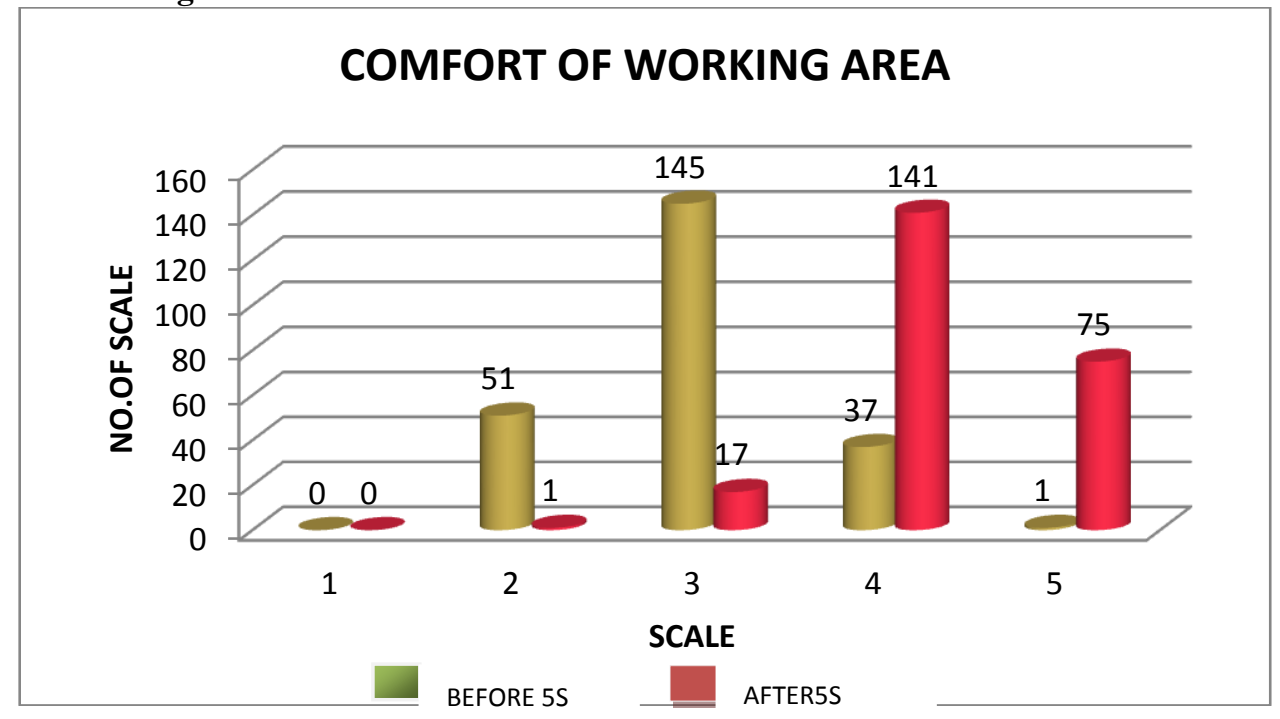

Overall impact

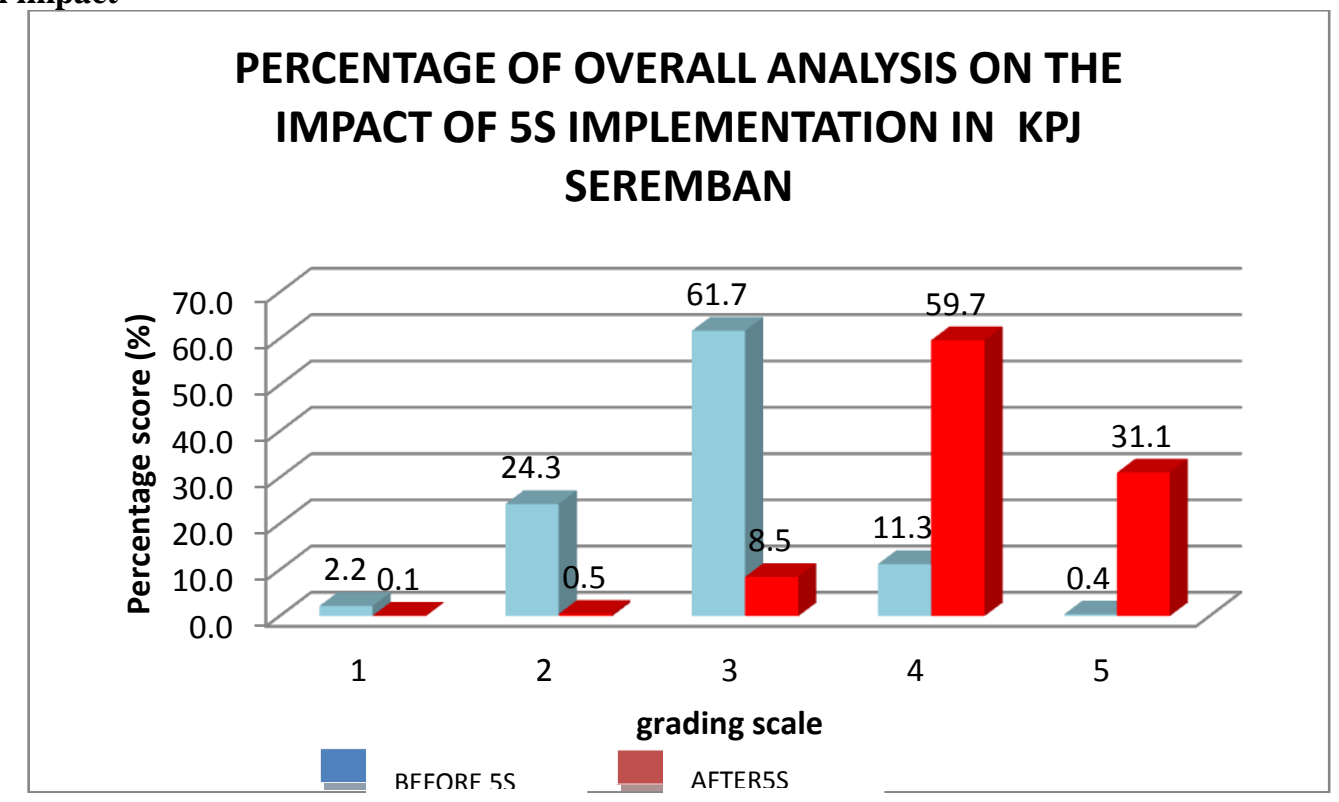

2. Data of survey for the second section- Knowledge and understanding i.question no. 1

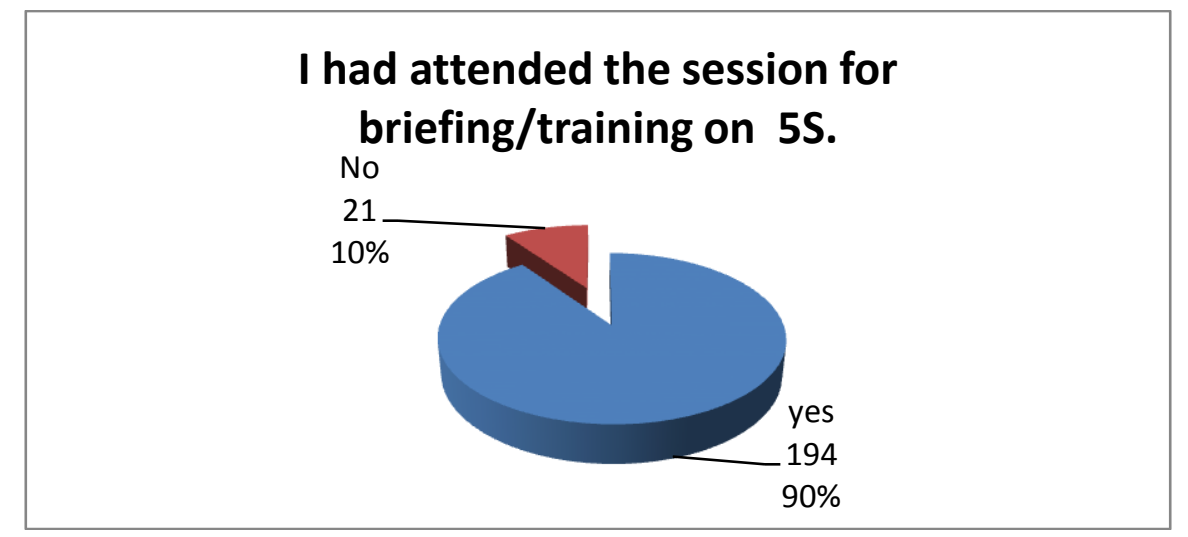


ii.question no. 2

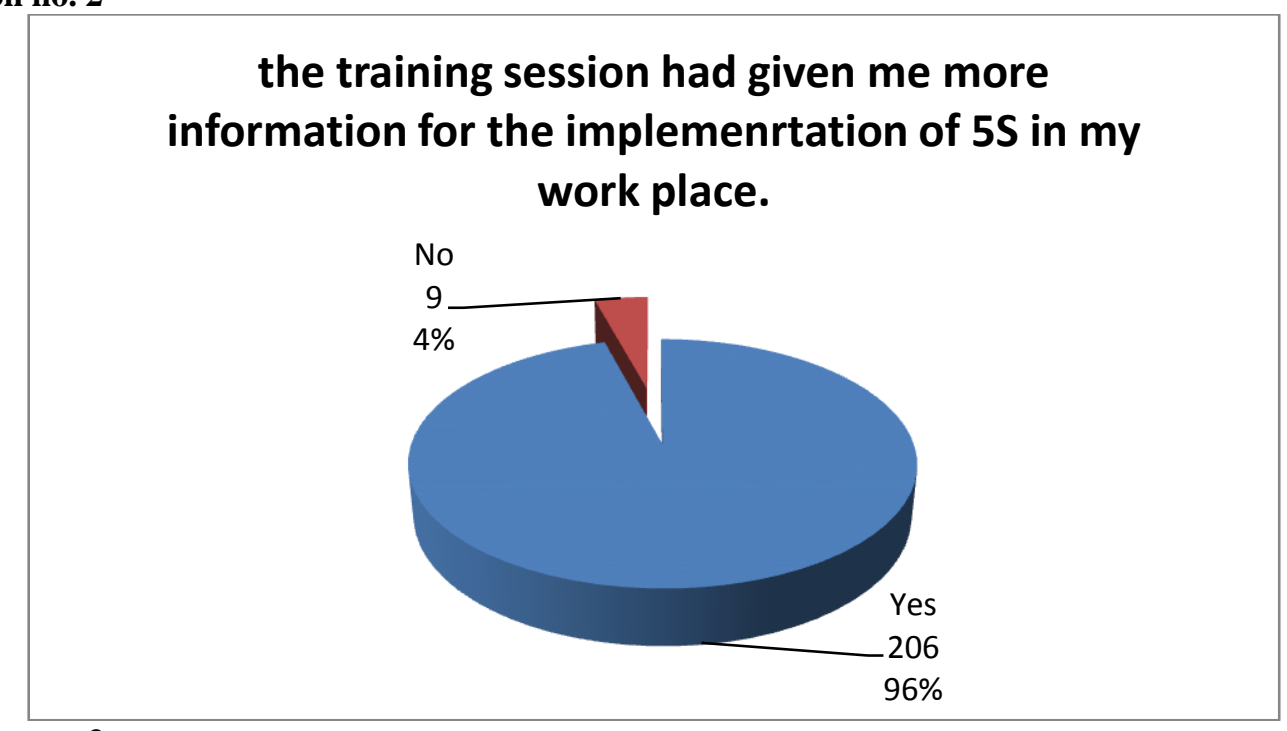

iii.question no.3

commitment towards the implementation of $5 \mathrm{~S}$ to ensure clean, safe and condusive working area.

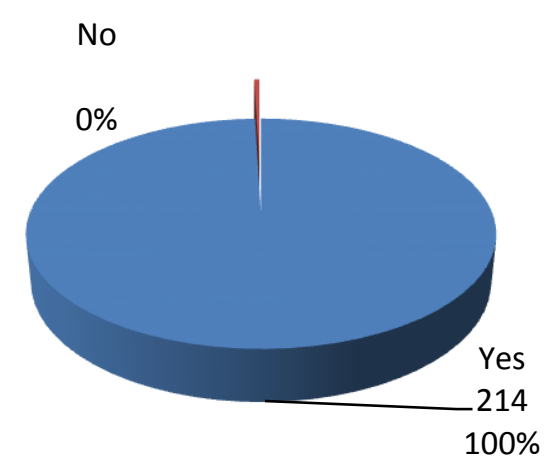

iv.question no. 4

items that had been segregated must be disposed immediately.

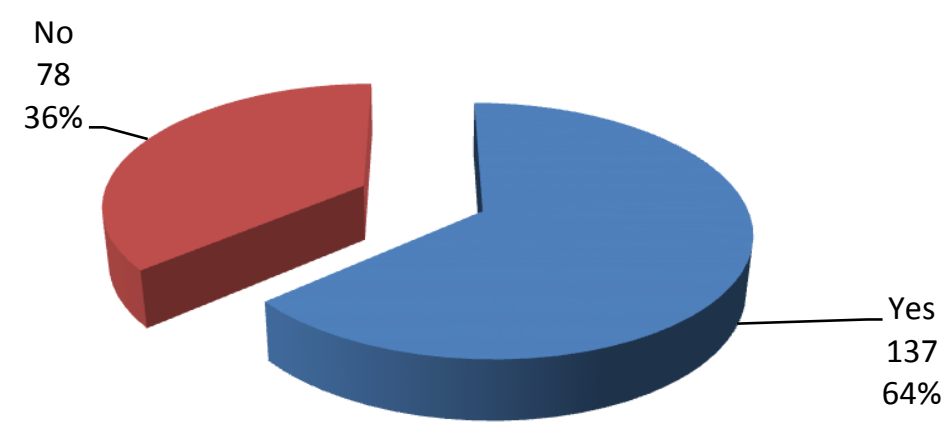


v. question no. 5

\section{arrangement is done to ensure easy excess to \\ pick items and easy to return back after use}

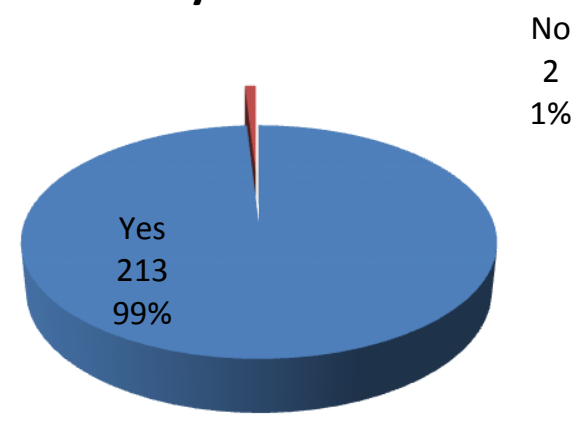

vi.question no.6

\section{there must be a schedule to ensure working} place is free from dust

No

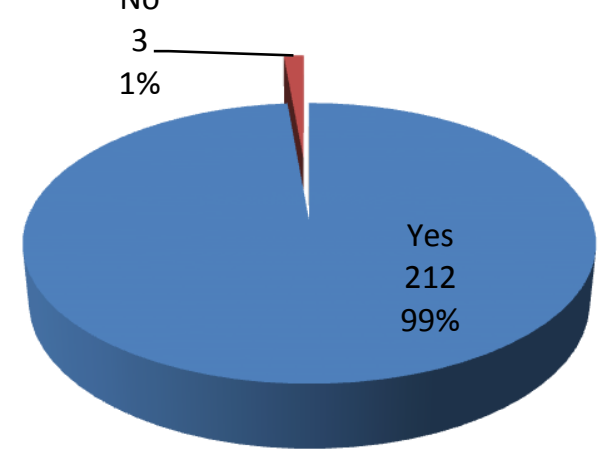

vii. question no. 7

\section{$5 S$ implementation is a good management system.}

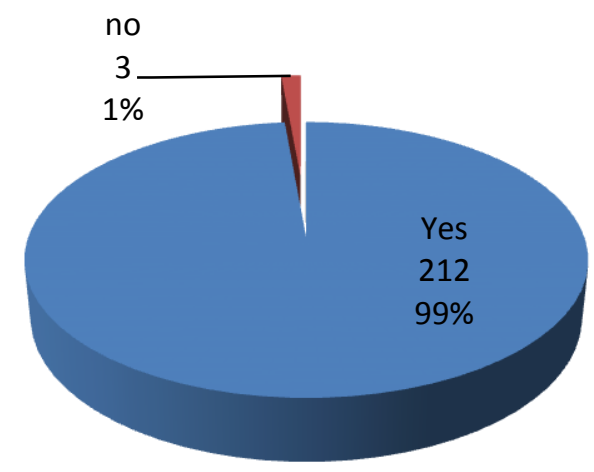

\section{Discussion}

Based on the survey, 234 staff (70.9\%) had participated with $68 \%$ coming from nursing services $21 \%$ from clinical support services ,9\% from support services $9 \%$ and $2 \%$ from management and medical professional. In term of the impact on productivity consisting of the arrangement of equipment and items in stor, file arrangement, work place, usage of equipment, time taken for searching, stock control, efficiency of space 
and cost saving we can see a big shift in term of scoring before the implementation of $5 \mathrm{~S}$ and after the implementation of $5 \mathrm{~S}$. The scoring before $5 \mathrm{~S}$ for all the elements to measue productivity were from poor to good .However after the implementation of $5 \mathrm{~S}$ the score had shifted from good to excellent where majority of staff gave their rating as very good while 26 staff rated as excellent for arrangement of equipment/items in stor, 92 for file arrangement, 76 for work place, 62 for usage of equipment, 76 for time taken for searching, 72 for stock control, 72 for efficiency of space and 56 for cost saving.

For the impact related to quality of work's place and proses in carrying out those works,the scores before $5 \mathrm{~S}$ implementation varies from poor to good for efficiency of work process, achievement of objectives, cleanliness, comfortability of rooms for general use and implementation of $3 \mathrm{R}$ program .However after the implementation of $5 \mathrm{~S}$ the scoring varies from good to excellent where the excellent rating for efficiency of work process was 60 , achievement of objectives was 85 , cleanliness was 83 , comfortability of rooms for general use was 70 and implementation of $3 \mathrm{R}$ program was 73 .

The same trend can be seen for the impact related to quality of staff and moral of workers, the scores before $5 \mathrm{~S}$ implementation varies from poor to good for awareness on 5S, teamwork, creativity and innovation, working culture, self discipline, communication and health status of staff. However after $5 \mathrm{~S}$ implementation the scores had shifted from good to excellent where the excellent rating for awareness on $5 \mathrm{~S}$ was 69 , teamwork was 82 , creativity and innovation was 83 , working culture was 72 , self discipline was 74 , communication was 79 and health status of staff was 62 . The finding from our survey is in line with the finding quoted by Pheng. $\mathrm{L}$ (2001) is his research about the impact of $5 \mathrm{~S}$ on the quality of the product

For the impact related to safety of work's place, the scores varies from poor to good before $5 \mathrm{~S}$ implementation for usage of equipment, risk of accident and comfort of working area.However after the implementation of $5 \mathrm{~S}$ the scores had shifted from good to excellent where the usage of equipment recorded a score of 70 for excellent, risk of accident with a score of 67 for excellent and comfort of working area with a score of 75 for excellent. The overall scores from the four impact varies from $2.2 \%$ for poor, $24.3 \%$ for fair, $61.7 \%$ for good, $11.3 \%$ for very good and $0.4 \%$ for excellent before $5 \mathrm{~S}$ implementation. On the other hand we can see a big shift after $5 \mathrm{~S}$ implementation with the scores varies from $0.1 \%$ for poor, $0.5 \%$ for fair, $8.5 \%$ for good, $59.7 \%$ for very good and 31.1\% for excellent.Based on the study conducted by Ansari.A and Modarress (1997), it was found that the implementation of $5 \mathrm{~S}$ had improved the safety in the organization.

Based on the data collected for the second section related to knowledge and understanding, it was found that $100 \%$ are comitted towards clean, safe and condusive working place, $64 \%$ agreed that after segregation items must be disposed immediately, $99 \%$ agreed on the important of arrangement for easy searching /putting back the items, $99 \%$ agreed on the important of schedule for cleaning of work place to ensure it is free from dust and $99 \%$ agreed that $5 \mathrm{~S}$ is a good management system.

Based on the study conducted by G.Arash and Z.Norzima(2013) on the impact of 5S implementation on industrial organization performance it was found that $5 \mathrm{~S}$ is an effective tool for improvement of organizational performance regardless of organization type, size, its production or its service. $5 \mathrm{~S}$ techniques would strongly support the objectives or organization to achieve continuous improvement and higher performance.

\section{Conclusion}

Based on the survey finding, it was found that before the implementation of $5 \mathrm{~S}$, the scores varies from poor to good( scoring from 1-3) related to the impact on productivity for quality of working place, quality and moral of staff and safety of work place .However after the implementation of $5 \mathrm{~S}$ the scores had changed which varies from good to excellent(scoring from 3-5). Regarding the second section of the survey which is related to knowledge and understanding ,the staff had given 100\% scoring for the commitment towardsclean, safe and condusive working place, $64 \%$ scoring on the necessity to immediately disposed items that had been segregated, 99\% scoring for the important of arrangement for easy searching /putting back the items, $99 \%$ scoring for the important of schedule for cleaning of work place to ensure it is free from dust and $99 \%$ scoring on the important of $5 \mathrm{~S}$ as a good management system

\section{Literature}

[1]. file:///C:/Users/abdaziz/Desktop/5S\%20\%28methodology\%29\%20-\%20Wikipedia,\%20the\%20free\%20encyclopedia.htm).

[2]. Sun, W., and Yanagawa, T (2006) Implementing Lean Manufacturing Concepts in Non-manufacturing Areas. The Technology Interface

[3]. Dulhai, G (2008) The 5S strategy for continuous improvement of the manufacturing processes in 49 autocar exhaust. Management \& Marketing, 3(4), 115-120.

[4]. Kilpatrick, J (2003) Lean Principles. Manufacturing Extension Partnership

[5]. Ho, S. M (1999) The 5S auditing. Managerial Auditing Journal, 14(6), 294-302.

[6]. Zidel, G. T (2006) A Lean Toolbox-Using Lean principles and techniques in Healthcare. Journal for Healthcare Quality, 28(1), 7-15

[7]. Esain. A, W. S., and Massey. L (2008) Combining Planned and Emergent Change in a Healthcare Lean Transformation. Public Money \& Management, 28(1), 21-26. 
[8]. Khamis, M. N. A. R., K.R.Jamaludin, A.R., Ismail, J.A., Ghani, Zulkifli. R. 2009. Development of 5S Practice Checklist for Manufacturing Industry. In World Congress on Engineering. London, UK

[9]. G.Arash and Z.Norzima (2013) The impact of 5S implementation on industrial organizations performance, International Journal of Business and Management Invention, 2(3) , 43-49

[10]. Ansari.A and Modarress .B(1997), World class strategies for safety : a Boeing approach, International Journal of Operations and Production Management,17(4) : p 389-398

[11]. Pheng.L (2001), Towards TQM -Integrating Japanese 5S principles with ISO 9001:2000 requirements. The TQM magazine ,13(5) : p. $334-341$ 